\title{
Sequence of Returns Risk for Islamic Investors
}

\author{
Brett Doran $^{1}$ \\ Michael E. Drew ${ }^{2}$ \\ Mahmood Nathie ${ }^{3}$
}

\begin{abstract}
For Islamic investors, sequencing risk is an omnipresent factor for retirement outcomes. This study shows that simple diversification can provide benefits to reducing the impact of sequencing risk. However, the results from the accumulation and distribution phases suggest that retirement products need to consider approaches that go beyond the received 'set-andforget' approach. The findings point rather to a more dynamic, whole-of-life approach to be adopted by Islamic retirement products.
\end{abstract}

\section{Introduction}

For long term investors, investing in equities is a critical component of any asset allocation strategy. Conventional wisdom suggests that stocks have provided superior returns over long the long run while acknowledging the puzzle regarding the magnitude of the equity risk premium, (Dimson, Marsh and Staunton, 2002; Mehra and Prescott, 2003). The historically measured equity premium has important implications for those saving for retirement, and has led pension funds to hold equities as the growth driver of the portfolio (Drew and Stanford, 2003). Recent data from the OECD Directorate for Financial and Enterprise Affairs (2011) reports that pension funds in countries such as the United States, Australia, Finland and Chile showed significant portfolio allocations to equities, in the range of 40 to 50 per cent. ${ }^{4}$

\footnotetext{
${ }^{1} \mathrm{PhD}$ Candidate, Department of Accounting, Finance and Economics, Griffith University

2 Professor of Finance, Department of Accounting, Finance and Economics, Griffith University

3 Senior Research Fellow, Department of Accounting, Finance and Economics, Griffith University

${ }^{4}$ While we do not discuss the optimum proportion of equities in this paper, we do note that it is an important question for the design of pension plans. For more detailed discussion see Basu and Drew (2010).
} 
For many pension plans around the world, the returns achieved from holding equities are the single most significant determinant of returns (and risk). This is also the case for Islamic investors, with a range of stock indices launched globally to facilitate participation in equity investments that are compatible with the principles of Shariah (Sadeghi, 2008). For instance, Dow Jones, FTSE, MSCI Barra and Standard \& Poor's now offer hundreds of Islamic equity indices (Hoepner, Rammal and Rezec, 2011). This type of financial innovation has facilitated the opportunity for Islamic investors to capture the equity premium identified in developed and emerging markets (Ariff, M., and V. Marisetty, 2012).

One of the key issues of concern for the rapidly growing Islamic financial services sector has been the investment performance and style of Islamic mutual funds (Abdullah, Hassan and Mohamad, 2007; Elfakhani and Hassan, 2007;Bashir and Nawang, 2011; Hoepner, et. al., 2011; Mansor and Bhatti, 2011) that follow Shariahcompliant equity screening practices (Derigs and Marzban, 2008). This stream of research is important as it garners positive insights into the risk and reward of Islamic mutual funds and Shariah-compliant stock selection. ${ }^{5}$

However, for pension plans, the framing of risk is more than simply the standard deviation of returns and the risk that an investment manager may under-perform an agreed benchmark on a risk-adjusted basis (Drew and Stanford, 2003b). It should also include management of the path dependency of outcomes, or the sequencing of returns (Basu, Byrne and Drew, 2011). The volatility in investment over the past decade prompted by global events (the dot.com bubble; sub-prime mortgages; the Global Financial Crisis and the European sovereign debt crisis) suggests that the ordering or sequencing of returns from investing in equities is one of the key drivers of retirement outcomes (Basu, Doran and Drew, 2012 and Doran, Drew and Walk, 2012).They find that sequencing of returns risk is one of the key determinants for retirement outcomes in defined-contribution plans (DC plans) ${ }^{6}$ and is a risk that needs careful consideration when designing the next generation of Islamic retirement products.

\footnotetext{
${ }^{5}$ A related area of research considers the issue of Shariah-compliant portfolio optimization (see Derigs and Marzban, 2009) and overall system design (Arif and Ahmad, 2012).

${ }^{6}$ Also favoured by Merton and others and dealt with extensively in Bodie, Z., McLeavey, D., $\&$ Siegel, L. B. (Eds.). (2008). The Future of Life-Cycle Saving and Investing (2 ed.): CFA Institute.
} 


\section{Relevant Literature}

Modern lifecycle investment theory has been enriched by the early works of Samuelson (1969) and Modigliani (1966).Their theories focused on consumer choice, in particular how much income to invest over ones' working life (accumulation stage) so as to have enough to spend in retirement (decumulation stage) (Bodie, McLeavey and Siegel, 2008). This 'consumption smoothing' process means reallocating lifetime investments by adjusting portfolio asset classes periodically to mitigate expected risk and produce positive returns. In this process, both Samuelson and Modigliani advocated holding constant portfolio weights over a persons' life(Ibbotson, Milvesky, Chen and Zhu, 2008). Fundamental to this debate are:(a) individuals' investment horizons and (b) psychological attitudes toward risk. Younger people may display more aggressive investment strategies. For instance, Bodie, Merton and Samuelson (1992) argue younger investors have greater propensity for risk as they experience more income flexibility in their early working lives and inclined to allocate more investable funds equities. On the other hand, older workers have less appetite for risk and more inclined to adjust portfolios later by reverting to gilt-edged securities. Hirt, Block and Basu (2006) also argue that individuals invest in more volatile assets in youth and then shift into more safer assets in later years.

There is however, no unanimity over this issue argued from the perspective of prudential investment principles. Basu and Drew (2010) find that greater exposure to equity investment in later years adds more value to retirement outcomes. They argue:

...two of the 'prudent investor' principles on asset allocation underlie most participant education programs: first, the existence of positive equity risk premium; and second, change in the investor's risk-taking capacity with age.

It is therefore not unusual when older-aged individuals resort to higher risk/return behaviour later in the lifecycle stage which suggests a greater reliance on high return strategies to supplement retirement income. Further, the plethora of asset allocation alternatives offered by mutual funds and managed funds has perceptively altered investment behaviour and created asset allocation and decision-making challenges in the way individuals exercise choice and preferences. Though these alternatives are inherently risk exposed by the nature of their underlying asset classes, it underlines the reality that some risk is desirable and tolerated if expected returns adequately compensate for risks undertaken. Siegel (Ibbotson et al., 2008, p. vii) argues that 'no investment is riskless if the 'run' is long enough". Methods used to mitigate risks include among others, adopting default investment options in consumer choice (Basu 
and Drew, 2010) and resorting to safe harbour options in retirement plans offered by institutions (Ibbotson et al., 2008).

As to the influence of psychological factors, it is argued that investors often exhibit behaviour inconsistent with rational choice (Thaler, 1993). Nor do they always display utility preferences by exercising strict axiomatic rational decision-making behaviour. In any case, notions of axiomatic behaviour are rebutted by Kahneman and Tversky (1986) on the grounds that behaviour is most often occasioned by psychological biases. What the studies suggests is that the sequencing process is complicated and not well understood, especially the magnitude of risk premiums.

The position is much the same under Islamic finance principles except for the exclusion of non-Shariah compliant equities, fixed income securities and derivatives from the asset class universe. In the broader Islamic finance literature, research related to lifecycle savings and investments remains relatively unexplored except for studies on Shariah-compliant pension options offered by takaful institutions (Butler, Simpson and Ziff, 2010). ${ }^{7}$ Partly because of this paucity in the broader literature Pollard and Samers (2007) argue that many Islamic financial practices remain 'under theorised'. It follows that in the absence of adequate research on Islamic lifecycle investments, the sequencing process for allocating proportions of investable funds across Shariah compliant asset classes over the long run remains largely conjectural. An exception is Chuodhry's (n.d.) 'accumulative valuation formula' that broadly defines individual asset classes for inclusion in wealth creation over an individuals' lifetime. The formula however, neither defines the proportions nor the order in which those assets are to be accumulated and held over an individuals' lifetime. Further, conforming to Shariah principles, the basket of investable assets defined in the formula exclude fixed income securities. While the formula is very detailed on the ethical dimension of investing, not much is theorised on the optimal mix of assets to be held in lifecycle portfolios during the accumulation and decumulation phases. Also, no strategy is implied in dealing with the risk of receiving negative returns or lower than expected returns during the decumulation stage - which remains a crucial concern to investors. Like all retirees, the main concern is the sequence of returns they expect in the future while living off their income and capital investments (Sandwick, 2011).

\footnotetext{
7. According to research conducted on behalf of NEST (National Employment Savings Trust, UK). Takaful institutions are Islamic cooperative insurance schemes.
} 
As retirement plans in many countries are now focussed on asset returns with minimal risk exposure and governments reluctant to provide guaranteed retirement safety nets, the responsibility for managing retirement assets has gradually shifted to retirees to make asset allocation decisions incorporating a broad spectrum of asset classes (Ibbotson, Milvesky, Chen and Zhu, 2008). For retirement savers this is a challenging issue as misallocation of assets funded from early human capital in the accumulation phase may result in disastrous end results when most needed in later years. Good investment strategies for the whole-of-retirement phase therefore presuppose adopting carefully constructed strategies aimed at maximising retirement wealth. Conventional lifecycle theory provides a number of 'glide-path' investment strategies setting out asset allocation preferences aimed at income smoothing in retirement (Kotlikoff, 2008). Properly reengineered, such strategies may benefit Islamic investors in retirement (Sandwick, 2009; 2010).

Scholars of Islamic finance argue that Islam is not averse to such conventional investment strategies to the extent they do not impinge on Shariah limits. (Iqbal and Wilson, 2005). They point to advances in indexing, innovative financial products and the emergence of Islamic mutual funds as examples (Jaffer, 2004). The strategies according to Iqbal (1999), entail mimicking two financial engineering approaches: "reverse engineering" and "innovation". The first involves remoulding conventional instruments by decomposing their constituents to determine their conformity with their closest substitutes in Islamic finance. The second is a "de novo" approach proposed by Iqbal and Mirakhor (2004, p. 58) under which products are designed from scratch referenced to a set of fundamental Islamic principles and then applying them to conventional finance instruments. The reliance on such approaches is evidenced in the growth of the sukuk market of where these approaches have been applied. However, early Islamic mutual funds relying on such innovative approaches have failed in their operations. ${ }^{8}$ Simulating the sequencing of returns using a combination of different asset classes as this study attempts, fall within the realm of these approaches.

It is possible then to construct well diversified portfolios where risks may be minimized with compliant asset classes. This may be achieved through the inclusion of sovereign securitised sukuks (bonds) in retirement portfolios (Alkhan 2006; Sandwick, 2009). By including the right mix of asset classes, the allocation become mostly straightforward once client needs (Sandwick, 2011) and the legal proscriptions are accommodated. These considerations are significant since saving for retirement to

${ }^{8}$ This relates to the failure of an Islamic unit trust set up by Kleinwort Benson in 1986. 
meet expected lifestyle changes is becoming a significant area of interest ${ }^{9}$ for individuals and managers in the Islamic wealth management industry (Lewis, 2005). It follows then that when the platforms for Islamic asset management are misunderstood, managers may undermine best-of-class portfolio allocation through asset misallocation. If so, retirement glide paths may carry significant downside risks for Islamic investors.

There is considerable activity in the Islamic wealth and asset management industry ${ }^{10}$ evidenced in professional and banking research. ${ }^{11}$ This level of interest is small compared to that existing in the conventional retirement industry partly because of: poor conceptualisation and misunderstanding of portfolio and risk management; ambivalence about uncertainty and the absence of best-of-class Shariah compliant risk instruments (Lewis, 2005). There is however, tacit acceptance among Islamic scholars that wealth creation strategies and value preservation in retirement savings, are essential elements in lifecycle investment (Iqbal and Wilson, 2005). Elgari (2004) maintains that in Islam a persons' wealth takes on a wider remit than merely chasing returns. One of these is recognising lifestyle changes that require securing future income to avoid dependence on kith and kin and third parties. ${ }^{12}$ Islamic financial institutions have been slow in providing lifestyle investing alternatives. Lewis (2005, p. 168) argues, that the industry seem to have been "somewhat ignored in favour of Islamic banking".

\section{Data}

The primary challenge facing this study is the lack of long-horizon data for Islamic equity indices. For instance, time series monthly data for the Dow Jones Islamic Market U.S. Index is only available across a 16 year period from December, 1995 until December, 2011. ${ }^{13}$ For a typical DC plan member, the accumulation phase may

\footnotetext{
${ }^{9}$ Sandwick, J. (2011, p.1) maintains: "There is US\$2.5 trillion or more in managed Muslim wealth worldwide, almost none managed according to the simple rules of shariah".

${ }^{10}$ Wealth management means managing the wealth of private individuals whereas asset management means managing the assets of institutions and corporate clients

${ }^{11}$ These include annual reports compiled by Ernst \& Young and Bank Sarasin Geneva

${ }^{12}$ A tradition (hadith) of Prophet Mohammad states: "it is better for you to leave your offspring wealthy than to leavethem poor".

${ }^{13}$ This index is commonly back-tested to December 1995 however the actual index began May 24, 1999. Other key indices, such as the S\&P500 Shariah Index and the MSCI USA Islamic Index both commenced in 2007.
} 
be forty years or more through their working life and, given the increase in life expectancy rates around the world, perhaps another two to three decades in retirement (International Monetary Fund, 2012). Hence we are faced with two options when running long run analysis on a short run dataset. We can simulate or back-test the database further and estimate the index's performance over a period two or three times that we have data for, or we can assume an accumulated balance at a point in a members' life. For the purpose of this study we have chosen the latter of the two approaches and propose observing the final 16 years of accumulation (from the start of age 50 to the end of age 65) and also the first 16 years of decumulation (from the start of age 66 to the end of age 81) for two different hypothetical U.S. citizens investing in Shariah compliant portfolios. However, prior to the empirical analysis of this study, we introduce sequencing risk using time-weighted measures which help inform and support the findings of what sequencing risk means for Islamic investors in the ensuing empirical simulation section of the study.

\section{Geometric and Arithmetic Returns}

Understanding sequencing risk requires knowledge of the methods in which investment returns are calculated. There are two common time-weighted approaches, arithmetic and geometric returns. The arithmetic return is merely an average of the returns across a period whilst the geometric return provides the compounded effect of returns over time and allows for the asymmetry between losses and returns.

There is only 16 years of data available for the Dow Jones Islamic Market U.S. Index from December, 1995 to December, 2011. The monthly arithmetic and geometric mean returns for this index during this period were 76 and 63 basis points respectively. However, whilst these are the average monthly returns if one invested at the beginning of the period, we are interested in what you're the average arithmetic and geometric returns would be if invested during this period (and held until the end of the period, that is, the end of December, 2011). Figure 1 below illustrates the average monthly returns experienced for a buy-and-hold investor investing in the Dow Jones Islamic Market U.S. Accumulation Index (DJIMUS). The month invested is represented by the horizontal axis whilst the vertical axis provides the monthly return. 


\section{Figure 1}

Monthly arithmetic and geometric returns experienced for a buy-and-hold investor investing at different stages from 1996 to end 2011

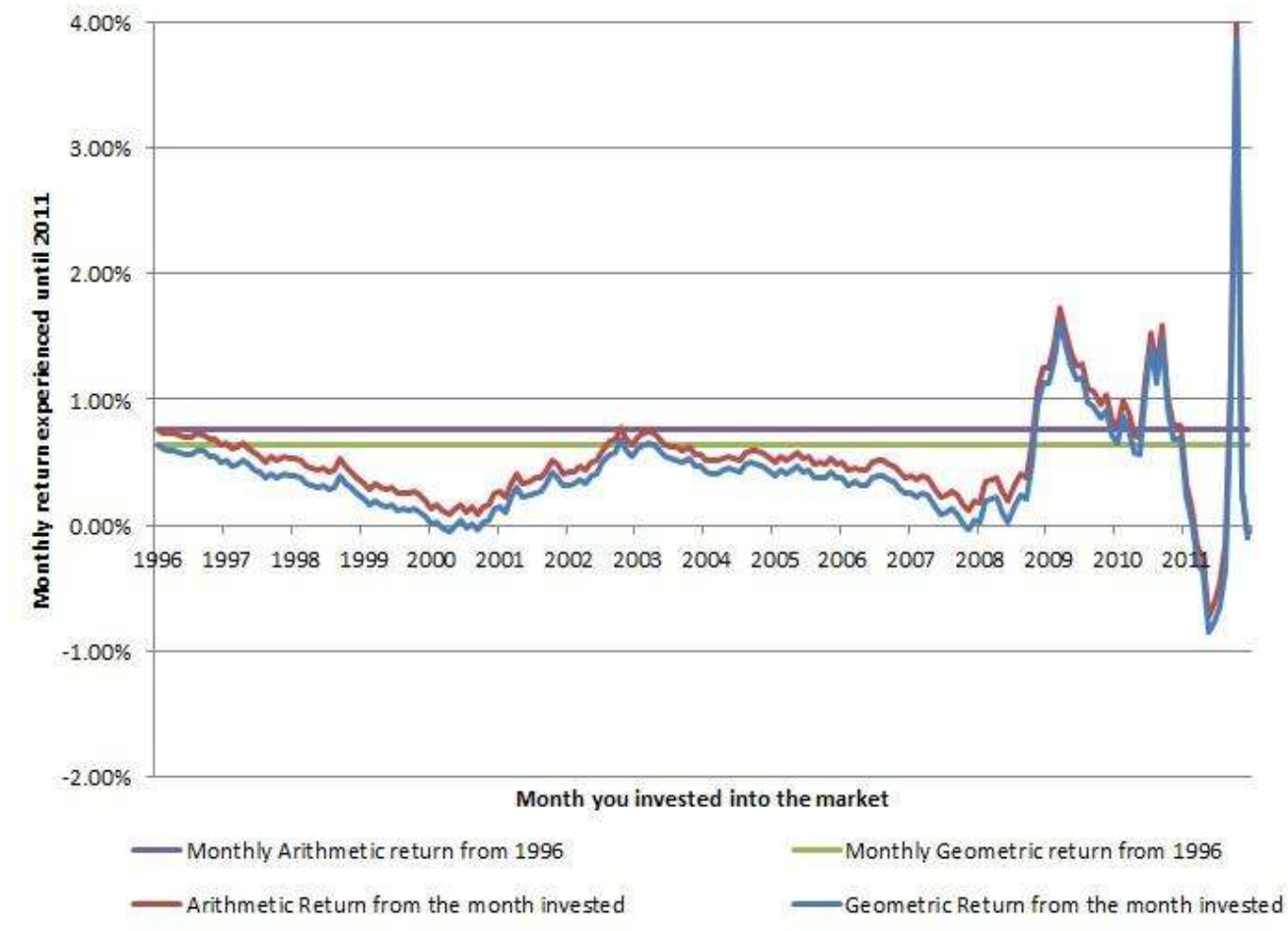

The purple (green) straight line represents the average monthly arithmetic (geometric) mean return experienced if the buy-and-hold investor purchased the DJIMUS Index at the beginning of 1996 and held the investment until the end of 2011. The red (blue) lines represent the average monthly arithmetic (geometric) returns which would be experienced by a buy-and-hold investor who invested in the month corresponding to the horizontal axis. Figure 1 illustrates the variations which would have been experienced by a buy-and-hold investor (investing until the end of 2011) purely through investing at different stages over the 16 year period from 1996 to 2011. Observing the blue geometric line, we conclude a buy-and-hold investor investing in the early months of the year 2000 would have experienced a somewhat negative average monthly geometric return from this date, which represents an 11 year period. This phenomenon occurs again for a buy-and-hold investor entering the DJIMUS Index towards the end of 2007 and also for the majority of 2011. 
This analysis has highlighted sequencing risk in a time-weighted manner and posed the idea that sequencing risk can arise when observing the timing in which an investor enters the market. Another point to note is that investors entering the market in 2003 as opposed to 2000 would have achieved a much greater rate of return, challenging the notion that equity returns are always superior in the long run. Whilst the timeweighted return analysis provides insight into when an investor enters the market can be a form of sequencing risk, it does not capture the traditional definition of sequencing risk as shown by Basu, Doran and Drew (2012). This study now follows a similar methodology to Basu et al. (2012) and illustrates sequencing risk impacting investors investing in Shariah compliant portfolios for the final 16 years of accumulation and the first 16 years of decumulation.

\section{Drivers of Sequence of Returns Risk for Retirement Investing}

There are four main drivers of sequencing risk: return volatility; contributions frequency; timing and growth; and finally the portfolio size. To illustrate the first of the main drivers for an Islamic investor into the future, we must find a way to examine the historical returns in a way which allows us to observe volatility over time. Figure 2 below illustrates a colour coded histogram of the monthly equity returns from the DJIMUS Index across a 16 year period from December, 1995 until December, 2011. The histogram has been divided into two colours to break the 16 years' worth of data we have into two 8 year periods. Each monthly return was placed into a return bucket representing returns in blocks of 5 per cent (-20 to -15 per cent is the first bucket and this moves up until the highest bucket of 10 to 15 per cent). There are two main insights which Figure 2 provides; the first is that the largest negative return for the entire data period has occurred in the second half of the data in October 2008. The second biggest take away from the histogram is the sheer change in where the data lies. The data in the second half of the period (red) has a far greater percentage of returns under 5 per cent when compared to the first half of the period (green). This observation highlights the first of the main drivers of sequencing risk, that being return volatility. 


\section{Figure 2}

Monthly histogram of the returns from the DJIMUS Index from 1996-2011, colour coded in to two equal 8 year periods.

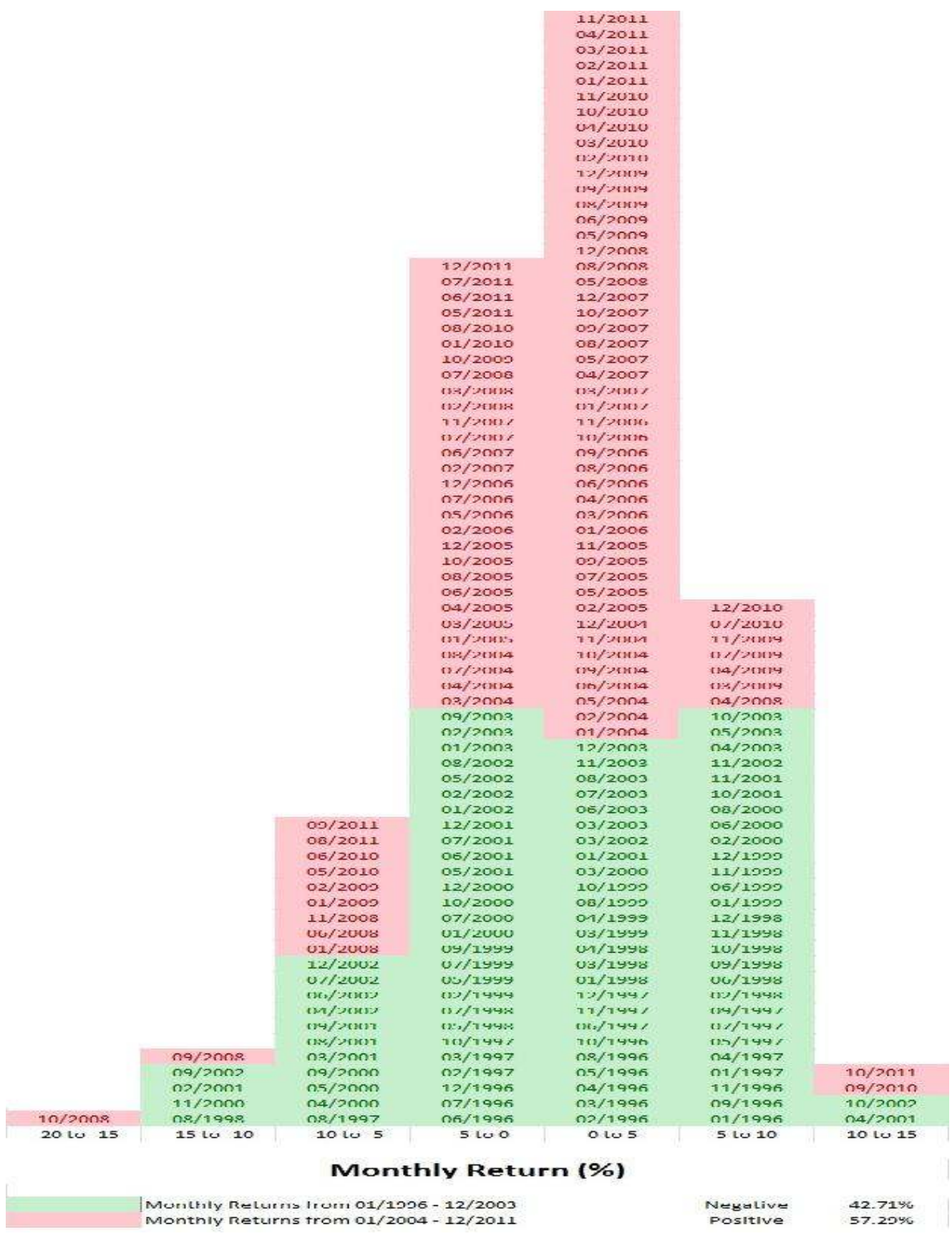


The second driver of sequencing risk is difficult to show graphically due to the sheer number of variations which individuals can have to their contribution profiles. For the purpose of this study, the following section assumes a 9 per cent contribution rate from paid employment with no starting balances or extra contributions. The common findings in the literature is that the greater the portion of total contributions made earlier in an accumulation period, the less impact sequencing risk will have on a portfolio (Johnston, Hatem and Thomas, 2010).With the knowledge of time diversification this makes intuitive sense. Basu et al. (2012) suggest that in reality portfolios are heavily back loaded with contributions, both through extra contributions made closer to retirement and also natural increases due to wage growth. This fact means that a larger percentage of total contributions are being subjected to a shorter time frame and have almost a toss of a coin chance $(42.71 \%$ from Figure 2) of the returns being negative month by month. Johnston et al. (2010) illustrate how the greater the starting balances of a portfolio, the lower the impact of sequencing risk results. ${ }^{14}$ This finding can also be related to front loading of contributions, commonly the longer contributions are exposed to returns the less of an impact sequencing risk will be. However, whilst we acknowledge the impact of different contribution profiles, the authors would like to reiterate they are very case specific and for this reason this study will not delve into complex modelling of hundreds of different profiles as the insight gained will be minimal to existing research. Continuing onto the third driver of sequencing risk, this study now follows a 16 year period of two U.S. citizens, one in the final years of accumulation, the other in the first years of decumulation (retirement).

\section{Methodology}

To observe the next two drivers of sequencing risk, this study constructs two hypothetical Islamic investors based in the U.S. contributing nine per cent of wage and salary to a defined contribution ("DC") plan. For simplicity, to illustrate sequencing risk we assume originally each of the Islamic investor's DC plan are allocating 100 per cent to growth assets (equities). We use this 100 per cent equities asset allocation to provide the base for our analysis into how diversification changes the impact of sequencing risk by providing a 60 per cent (equities) and 40 per cent to defensive assets (bonds) rebalanced annually. ${ }^{15}$

\footnotetext{
14 This finding is intuitive as there is a greater percentage of total contributions which are experiencing all the returns over the period.

15 The authors stress that we are in no way inferring that a 100 per cent equity asset allocation is an appropriate approach to retirement investing. This original asset allocation is being used as a proxy to show how diversification changes the impact of sequencing risk.
} 
We require developing two different individuals to test the impact of sequencing risk in the accumulation and decumulation phases. Various assumptions are required around wage growth, expected inflation and returns prior to the time we have data. For simplicity, we assume our age 50 worker and age 66 worker turn these respective ages on January 1, 2012. We then assume the data we have, from January, 1996 December, 2011 will repeat again from January, 2012 - December, 2027. In order to estimate the sequence of returns risk faced by Islamic investors, we need to make some simplifying assumptions about our 'typical' DC plan member. We consider the case of two 'average' U.S. workers contributing nine per cent (six per cent employee; three per cent employer match) over forty-one years of working life (commencing work at age 25 and retiring at the end of age 65). ${ }^{16}$ As we plan to shorten the long run analysis to only 16 year windows, we assume a constant annual rate of return over the years prior to our analysis equal to that of the 100 per cent equity investment from 1996 to 2011 which works out at 9.18 per cent per annum. This assumption produces two accumulated portfolio balances for the worker age 50 and for the retiree aged 66 which are shown in Table 3.

A further assumption is how best to consider the two individuals career earnings experience over their career stages. We take the approach of Byrne, Blake, Cairns and Dowd (2006) and consider a profile that incorporates relatively rapid promotion in the earlier years of the employee's career, with a peak in the mid-to-late 40s, and below-average promotional increments thereafter (see Appendix One) ${ }^{17}$ In addition to the 'humped' promotion profile, we assume that the employee will also experience an annual increase in wages arising from aggregate productivity advancements of 2 per cent per annum along with an expected inflation rate of 2 per cent per annum. ${ }^{18}$

The table below offer a summary of the respective assumptions and accumulated final account balances for the two hypothetical U.S. citizens.

\footnotetext{
${ }^{16}$ Munnell and Sunden (2006) find that nine per cent is the typical contribution rate for a U.S. 401(k) plan.

${ }^{17}$ We also note the limitations of assuming that the 'typical' worker is in full time employment (with no risk of unemployment) for their entire career. For issues of gender, career breaks and DC plan design, see Basu and Drew (2009).

${ }^{18}$ An assumption of a 2 per cent per annum real wage increase is common in the DC plan literature, see Bryne et al., (2006) and Basu and Drew (2010). The assumption 2 per cent inflation per annum stems from the recent move of the U.S. Federal reserve setting a target inflation rate of 2 per cent, which represents an approximate value alike other major economies.
} 


\section{Table 1}

Key assumptions for the two hypothetical U.S. citizens (one in the final 16 years of accumulation and the other in the first 16 years of decumulation) investing in Shariah compliant portfolios.

\begin{tabular}{|c|c|c|}
\hline & Accumulation & Decumulation \\
\hline Age analysis begins & 50 & 66 \\
\hline Age analysis ends & $\begin{array}{l}\text { End of age } 65 \\
\text { (retire at } 66 \text { ) }\end{array}$ & $\begin{array}{l}\text { End of age } 81 \\
\text { (life expectancy } 82 \text { years) }\end{array}$ \\
\hline $\begin{array}{l}\text { Annual Salary/Drawdown } \\
\text { as at January } 2012^{\mathrm{a}, \mathrm{b}}\end{array}$ & $\$ 51,896$ (age 50) & $\$ 21,275$ (age 66) \\
\hline Contributions (Monthly) & $9 \%$ & N/A \\
\hline $\begin{array}{l}\text { Withdrawal rate (WR) } \\
\text { (Indexed to Inflation) }\end{array}$ & N/A & $5 \%+$ inflation \\
\hline Inflation $^{\mathrm{c}}$ & $2 \%$ & $2 \%$ \\
\hline Balance as of $2012^{\mathrm{d}}$ & $\$ 203,249$ & $\$ 425,491$ \\
\hline Total Contributions (lifetime) & $\$ 175,652$ & $\$ 78,458$ \\
\hline
\end{tabular}

\footnotetext{
${ }^{\text {a }}$ Representative of the median wage for a U.S. worker in the respective age brackets (Bureau of Labor Statistics). The drawdown is representative of 5 per cent withdrawal of the retirement balance and is indexed to inflation of 2 per cent per annum. This value was originally derived from the 5 per cent withdrawal rate though is also a close representation of median annual income for persons aged over 65 in the U.S. which was $\$ 19,960$ for the year ending 2010, applying an approximate inflation adjusted (2 per cent) to the year ending 2012 this would be $\$ 20,766$ (U.S. Department of Commerce, 2011)

${ }^{\mathrm{b}}$ We use a humped lifetime wage growth profile as per Byrne et. al. (2006) and assume 2 per cent inflation and 2 per cent aggregate productivity growth.

${ }^{c}$ This is consistent with U.S. Federal Reserve's policy (Jan 2012) in regards to setting a 2 per cent target rate of inflation. This inflation figure was also used to adjust the monthly withdrawals.

${ }^{\mathrm{d}}$ This balance was found by applying the above assumptions from a starting age of 25 . We back dated the wage growth profile from the salary as of January, 2012 to find the estimated salary at age 25 . The portfolios experienced the average annual rate of return for a portfolio invested 100 per cent in the Dow Jones Islamic Market U.S. Index for the years prior to the analysis.
} 
To simulate sequencing risk, we adopt a methodology from Basu et al. (2012). The paper held all inputs, including the distribution characteristics of the data, constant. The method requires not only all assumptions around contributions and wage growth to remain constant but also the four moments of the distribution to be held constant. The methodology used to create this form of simulation is known as a Bootstrap empirical distribution where by the data is sampled from without replacement. Essentially the data is shuffled multiple times. This paper will shuffle the data $(n=192) 10,000$ times to create 10,000 different wealth outcomes that we are then able to use as a comparator to the actual path. ${ }^{19}$ The actual path is assumed to be the January, 1996 - December, 2011 paths occurring again from January, 2012 December, 2027. The study now breaks into two sub-sections, the first will capture the analysis for the accumulating portfolio (final 16 years of employment) whilst the second section will illustrate the decumulating portfolio (first 16 years of retirement). Both sections incorporate analysis into the 100 per cent growth portfolio (invested entirely in the DJIMUS Index) and analysis into a diversified portfolio, that being a 60 per cent growth ( DJIMUS Index) and 40 per cent risk free assets. ${ }^{20}$

\section{Accumulation portfolio}

\section{(a) 100 per cent growth portfolio (Dow Jones Islamic Market U.S. Index)}

The balance at age 50 for the hypothetical U.S. citizen investing in 100 per cent equities (DJIMUS Index) is $\$ 203,249$ (as per Table 1). We assume the actual path from 1996-2011 will occur again from 2012 to 2027. Figure 3 below illustrates the percentiles of the bootstrap. The actual path is depicted by the thick black line.We can see the path had superior performance at the beginning of the period, however the negative returns generated after this period dragged the accumulation path down and it ended up in the $11^{\text {th }}$ percentile of the distribution of final portfolio balance outcomes. This finding highlights that the DJIMUS Index has been severely impacted by sequencing risk over the period from 1996 to 2011 for an accumulation investor. Note, the graph can be somewhat confusing as the lines coloured in a red tone are on

\footnotetext{
${ }^{19}$ The authors would like to clarify that 10,000 paths is by no means capturing all the possible paths available to us. The true number of paths is a factorial of $192(192 \times 191 \times 190 \times \ldots \times$ 1) which when calculated on any standard software such as excel provides a number greater than excel can evaluate and excel returns an infinite reading.

${ }^{20}$ Risk-free rate is made available by Professor Ken French (Dartmouth) for researchers and we acknowledge and thank him for this data
} 
the top for the majority of the time period. This is because they have experienced the best returns early and get severely impacted at the end of the period; the percentiles are measured as of the portfolio values at the end of the period.

\section{Figure 3}

Bootstrap simulation $(10,000$ paths $)$ of the 100 per cent growth portfolio in the final 16 years of accumulation using the assumptions from Table 1 .

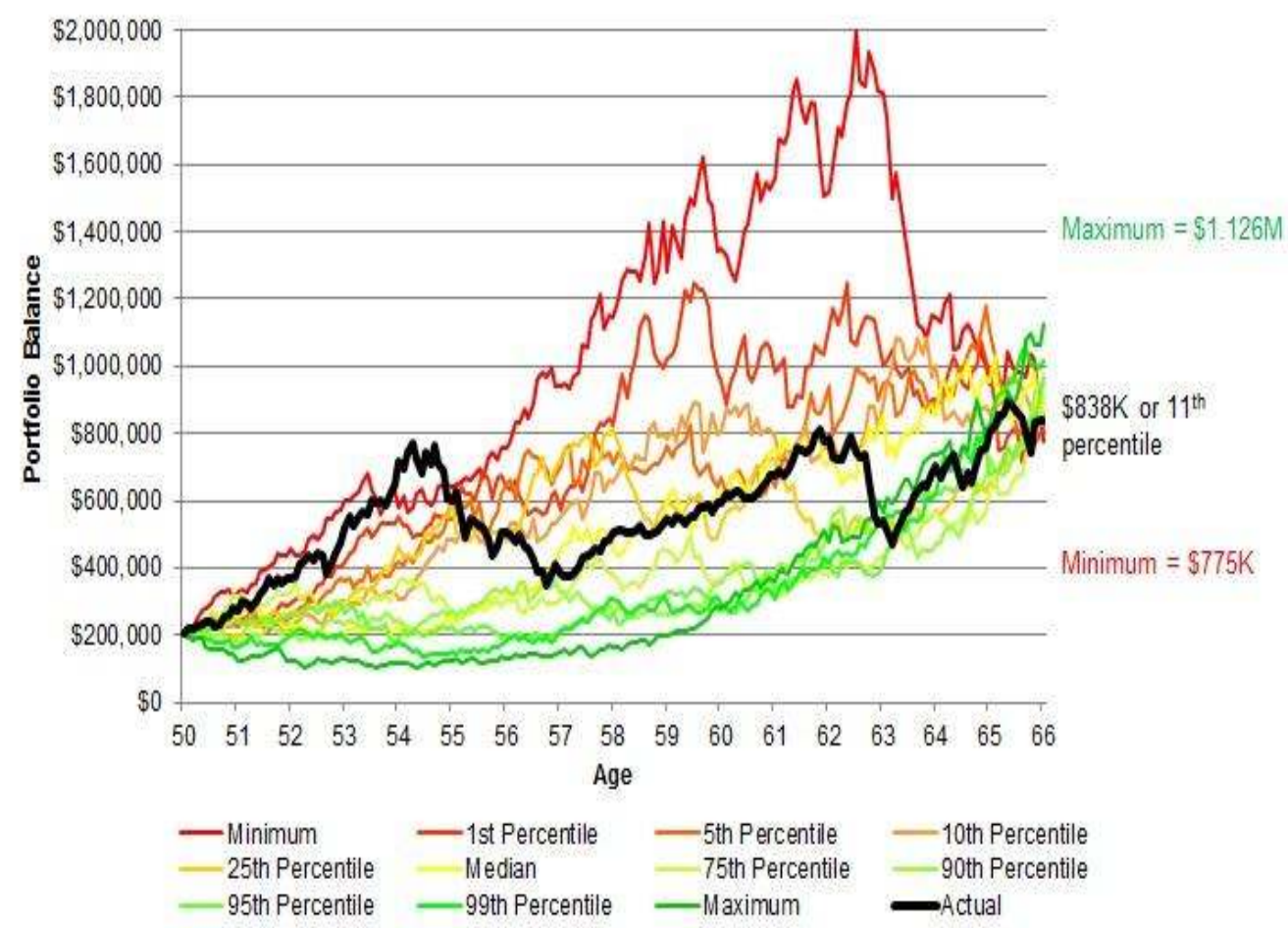

(b) A 60/40 portfolio (growth/defensive) - (Dow Jones Islamic Market U.S.

(c) Index/Risk-free rate of return)

The diversified portfolio provides some interesting analysis. Once again, all assumptions around wage growth and accumulated balances are constant as per Table 3. The bootstrap empirical distribution of sampling without replacement is run again 10,000 times and in Figure 4 below the percentiles along with the actual path (from 1996-2011 which is assumed to occur again from 2012-2027) is displayed by the thick black line. 


\section{Figure 4}

Bootstrap simulation (10,000 paths) of the $60 / 40$ per cent growth/defensive portfolio in the final 16 years of accumulation using the assumptions from Table 1

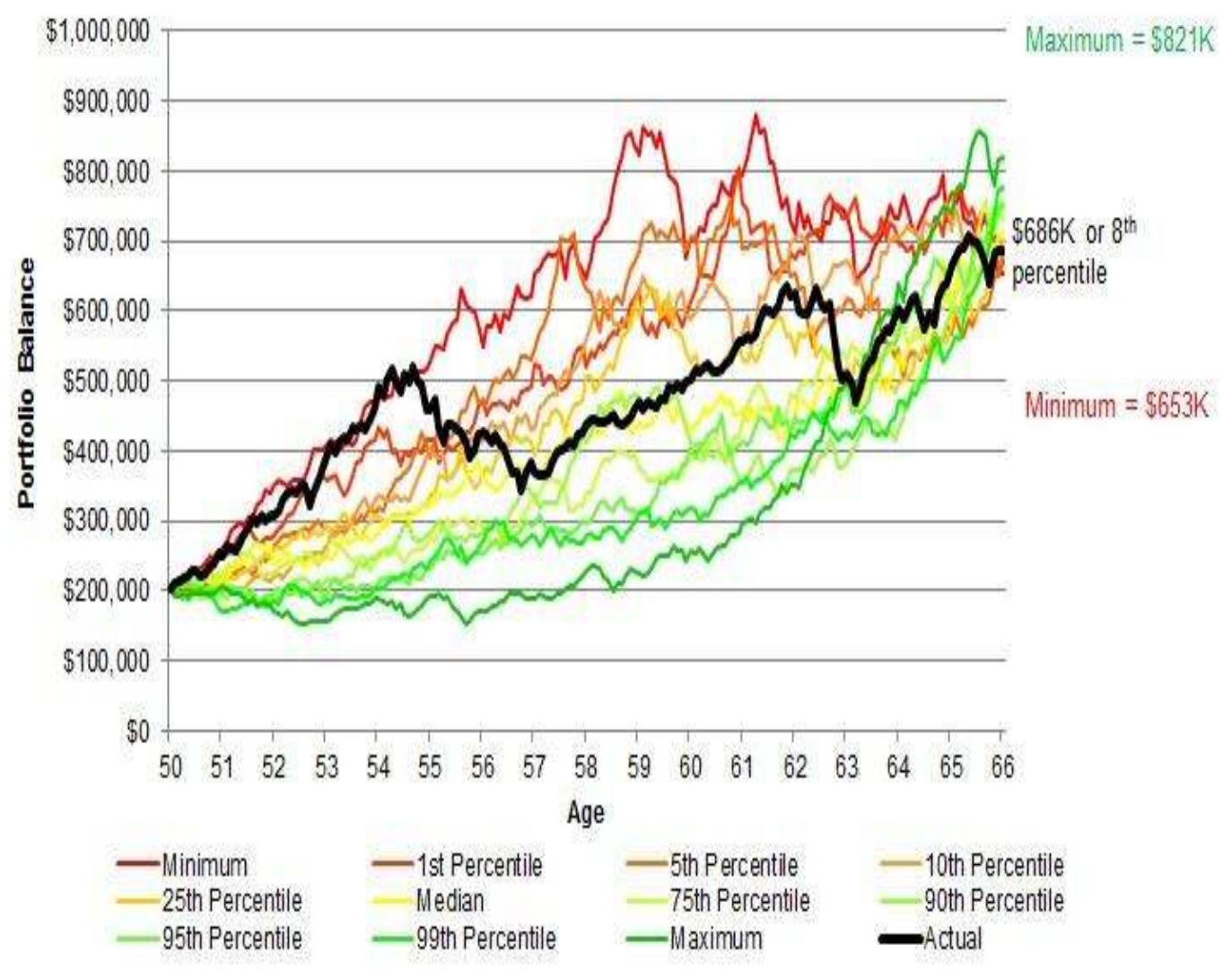

The most interesting insight Figure 4 provides is when compared to Figure 3. The diversified portfolio has actually been subjected to a greater amount of sequencing risk as it now falls in the $8^{\text {th }}$ percentile rather than the $11^{\text {th }}$ percentile. The maximum of the 10,000 bootstrap $(\$ 821 \mathrm{~K})$ also does not achieve the actual path in the 100 per cent growth portfolio ( $\$ 838 \mathrm{~K})$. These two facts highlight that merely diversifying the portfolio does fix the issue of sequencing risk, and in this case the impact has actually increased. 


\section{Decumulation Portfolio}

\section{(a) A 100 per cent growth portfolio (Dow Jones Islamic Market U.S. Index)}

The decumulation (retirement) analysis has a terminal wealth balance at the start of age 66 of $\$ 425,491$ as recorded in Table 3. The U.S. citizen is beginning retirement on January 1, 2012 and the analysis will capture a 16 year period to December 31, 2027. The final salary prior retirement was $\$ 48,100$ per annum and represents the median wage for a U.S. worker aged 65 (Bureau of Labor Statistics, 2012). This annual wage was back-dated with our wage growth assumptions to find each annual salary to age 25; we were then able to generate an accumulation path from this data which worked out to the value of $\$ 425,491$. These two figures allow us to produce a retirement wealth ratio (RWR), a commonly used statistic in the literature and it displays the terminal wealth balance as a multiple of final salary. The RWR for this calculation is just under 9 times and helps support that $\$ 425,491$ is a realistic value (see Basu and Drew, 2009b; 2010 and Antolin, Payet and Yermo, 2010).

There were two options available to determine a reasonable withdrawal rate (WR).AWRis a percentage of the total portfolio or a dollar value which represents the requirements to suit living standards in the United States. The literature provides varying WR's, from safe WR's (Finke, Pfau and William, 2012) to WR's across a series of percentiles, e.g. 4\%, 5\%, 6\%, .. 10\% (Woerheide and Nanigian, 2012; Frank et. al., 2010; 2011). When looking at minimum requirements for living standards in the U.S. the median annual income for persons aged over 65 in the U.S. was found to be $\$ 19,960$ for the year ending 2010.Applying an approximate inflation adjusted ( 2 per cent) to the year ending 2012 this would be $\$ 20,766$ (U.S. Department of Commerce, 2011). With this figure in mind, we tested to see what WR this would bring about. It represents just below a 5 per cent WR in the first year. As this figure is commonly used in the literature (Frank et. al., 2010; 2011) we concluded the 5 per cent WR indexed to the 2 per cent inflation per annum (which was allowed to compound monthly at $2 / 12$ per cent per month) would provide the methodology for the decumulation analysis of the study.

Figure 5 below illustrates the 100 per cent growth (DJIMUS Index) portfolio for the retiree. 


\section{Figure 5}

Bootstrap simulation (10,000 paths) of the 100 per cent growth portfolio in the first 16 years of decumulation using the assumptions from Table 1

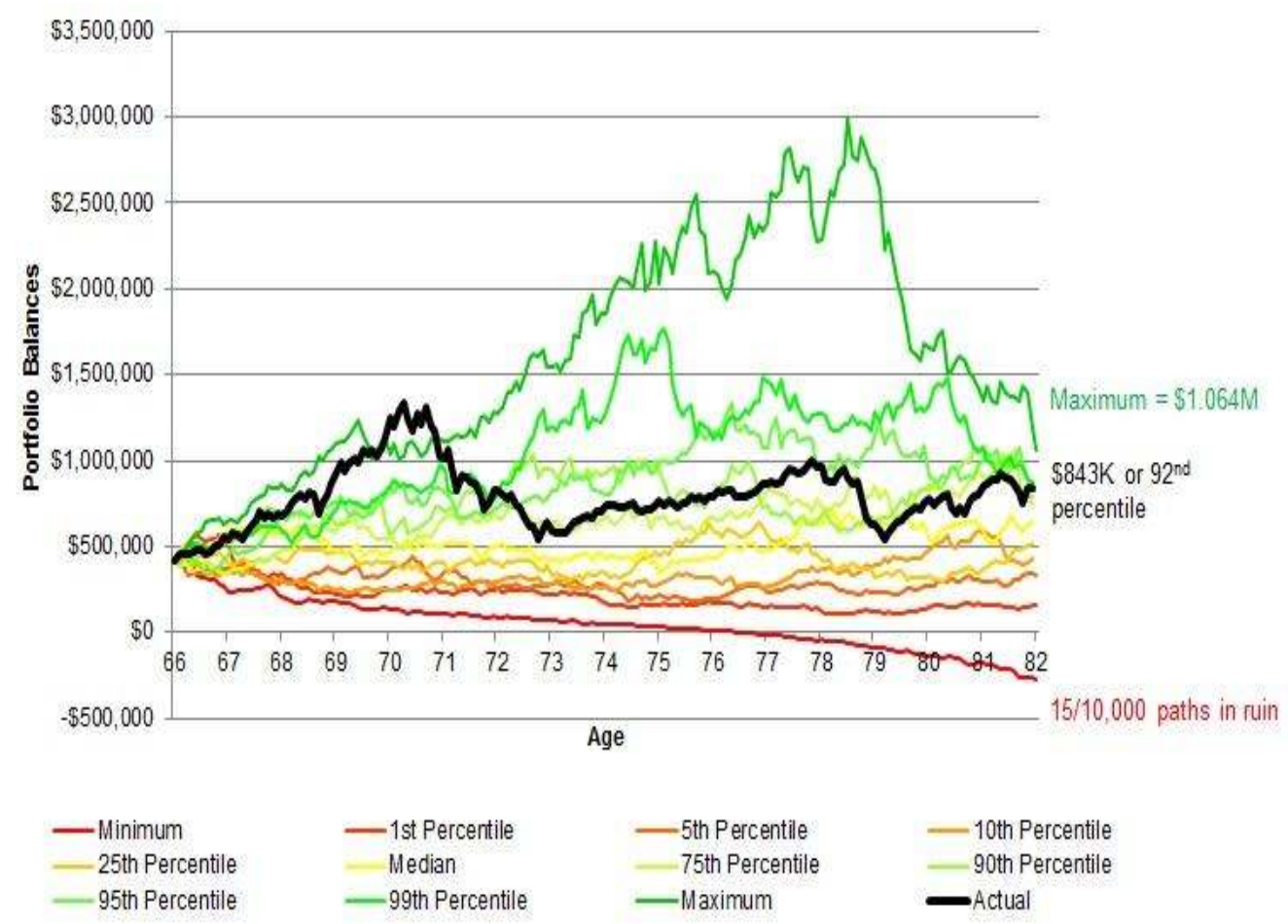

The 100 per cent growth portfolio has achieved an exceptional outcome for the actual path; the total portfolio value has almost doubled over the 16 years even though the portfolio was withdrawing 5 per cent per annum indexed to 2 per cent inflation per annum. This is due to the DJIMUS Index achieving superior results in the early years of retirement when the portfolio had the highest monetary value and exploiting the portfolio size effect (Basu and Drew, 2009b). The actual path experienced is seen to have superior sequencing for retiree's though poor sequencing for those in late accumulation, as shown in section VII. There were 15 of the 10,000 paths which ended in ruin in the simulation and a range between the percentiles of over $\$ 1$ Million. 
60/40 portfolio (growth/defensive) - (Dow Jones Islamic Market U.S. Index/Risk-free rate of return)

Once again we are able to illustrate how a simply diversified portfolio of 60 per cent in growth in the DJIMUS Index and 40 per cent defensive (risk-free rate) is able to impact the sequence of returns. Figure 6 below displays the diversified portfolio.

\section{Figure 6}

Bootstrap simulation $(10,000$ paths $)$ of the $60 / 40$ per cent growth/defensive portfolio in the first 16 years of decumulation using the assumptions from Table 1

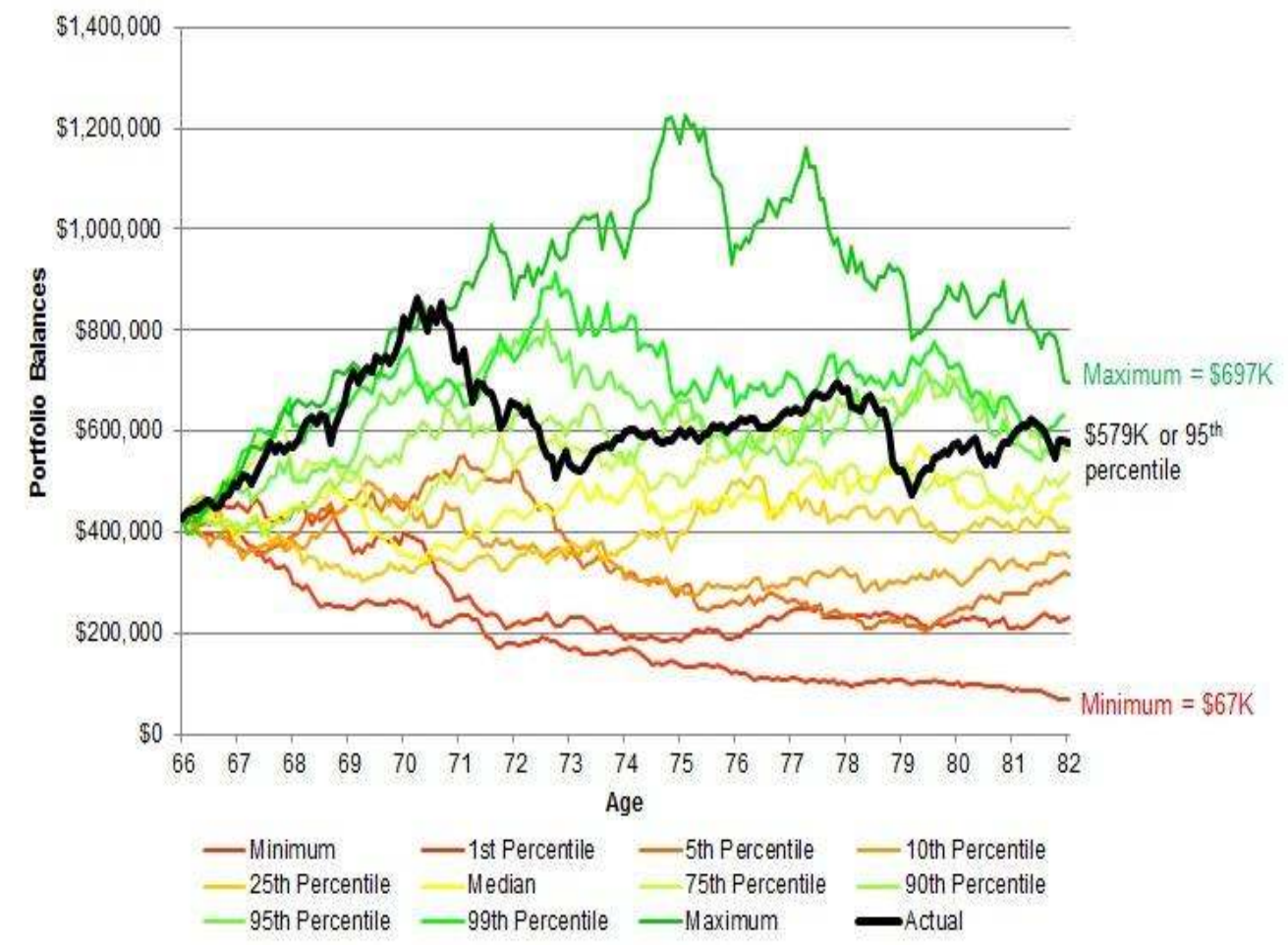

The diversified portfolio offers interesting insights into what asset allocation is optimal over time. As seen in section VII, the 100 per cent growth portfolio was superior as the actual path experienced achieved a higher percentile than the actual path in the diversified portfolio and it also achieved a higher value than the maximum path in the diversified portfolio simulation. However, when observing the retirement paths in section VIII, we can see the diversified portfolio has achieved a higher 
percentile in comparison to the 100 per cent growth portfolio $\left(95^{\text {th }}\right.$ percentile against $92^{\text {nd }}$ percentile). We are also able to observe that whilst 15 of the 10,000 paths in the 100 per cent growth portfolio ended in ruin, the diversified portfolio was able to boast no paths of the 10,000 being in ruin, with the minimum simulated path still having $\$ 67 \mathrm{~K}$ after 16 years. The diversified portfolio has reduced the distribution of outcomes to a range of about $\$ 630 \mathrm{~K}$. Whilst the actual paths dollar values are quite in favour of the 100 per cent growth portfolio, when comparing these two portfolios on a probability of failure measure of success, the diversified portfolio is the clear winner.

\section{Discussion of results}

The analysis in Sections VII and VIII have shown sequencing risk can have both an increased and decreased impact when diversification is introduced into the portfolio. Section VII highlighted that the 100 per cent growth portfolio was superior in the final stages of accumulation, though in Section VIII over the same set of data, on a probability of failure analysis, the diversified portfolio was superior. This highlights that a constant asset allocation is not adequate at achieving the optimal portfolio over time. The insight the analysis provides is intuitive, a younger person may be able to take on larger amounts of risk (growth) in a portfolio as they are able to recover before retirement. A person near, or at retirement, may not be able to take on the same level of risk as the event of a large downturn in the market would impact their portfolio significant - which links to the portfolio size effect (Basu and Drew, 2009b).

We are able to link the analysis shown in Sections VII and VIII with the original geometric return analysis in Section IV of this study. Each contribution in the "actual path" (Black line in the Figures in Sections VII and VIII) was earning their corresponding geometric returns shown in Section IV. This comparison also helps us highlight how our short-run analysis has a potential upside bias. The accumulated balances we have used have experienced the horizontal line geometric returns in Figure 1 (Section IV). These geometric returns were much greater than the majority of the other contributions return paths and ensured a large percentage of returns achieved superior results. A long run analysis would perhaps show more contributions beyond a 16 year period having a very small monthly geometric return average. We can also draw on findings from Johnston et al. (2010) who showed a larger starting balance reduces the impact of sequencing risk. The analysis in this study has essentially looked at portfolios over a 16 year period which had large starting balances and thus the impact of sequencing risk is not being completely 
captured by this study due to the limitation around data. To provide intuitive explanation of this, look at one of the simulation Figures in Section VII (Accumulation), where the final account balance has a large distribution of outcomes around the final account balance. In a long-run analysis, this same distribution of outcomes would be seen around our starting balances. With this intuitive knowledge, it can be argued to be much worse in a long run realistic simulation.

Lifecycle strategies are an emerging strategy which attempt to reduce the impact of sequencing risk for retirement investors. These strategies create a "glide path" over a person's working life which reduces the exposure to risky assets as the portfolio size grows and a larger dollar amount is being exposed to market returns. The term "glide path" reflects the idea behind a plane coming into land; a long sloping decline is the universal approach to landing a plane to reach their desired landing location whilst minimizing fuel consumption (or in this case, finding the optimal path between foregone gains and potential losses in market returns). ${ }^{21}$

Finding the optimal glide path is a very member-specific task for a superfund as members can have different risk tolerances and retirement needs. The core design behind the glide paths is also a hotly debated topic in the literature (Basu and Drew, 2009b; Basu et al., 2011). Papers have researched into glide paths which are both static (set and forget with pre-determined decline in risk tailored to a member's age) and dynamic in nature (change asset allocations periodically in response to experienced returns or portfolio size). Whilst this study acknowledges the need for research into finding the optimal glide path, the original objective of this study was to inform the idea of sequencing risk for Islamic investors. The authors will not diverge into solving the problem of sequencing risk in this study. Rather, it will leave this problem to future Islamic finance researchers who can use the findings in this report to inform the importance of their work.

\section{Conclusion}

One of the key learning's from the study is that, for Islamic investors, sequencing risk is an omnipresent factor for retirement outcomes. This study has shown simple diversification can provide benefits to reducing the impact of sequencing risk. However, the results from the accumulation and distribution phases suggest that retirement products need to consider approaches that go beyond the received 'set-andforget' approach. The findings point rather to a more dynamic, whole-of-life

21 For an article on how glide paths help reduce planes fuel consumption, see http://www.nasa.gov/centers/ames/news/releases/2006/06 70AR.html 
approach to be adopted by Islamic retirement products. These strategies aim to find the optimal asset allocation for individual members so that not only are retirement objectives met, they are done so through minimizing risks which increase over time, such as sequencing risk. The objective of such strategies, and subsequently this research, is to change the debate from the current time-weighted approach to returns (and risk) and move the focus to objectives that matter for Islamic investors, that is, dollar-weighted return outcomes.

\section{Reference List}

Alkhan, R. K. (2006). Islamic Securitization: A Revolution in the Banking Industry. Bahrain: Miracle Graphics.

Abdullah, F., T. Hassan, and S. Mohamad, 2007, Investigation of performance of Malaysian Islamic unit trust funds, Managerial Finance, 33(2), 142-53.

Antolin, P., S. Payet, and J. Yermo, 2010, 'Assessing Default Investment Strategies in Defined Contribution Pension Plans', OECD Working Papers on Finance, Insurance and Private Pensions, No. 2, Retrieved from http://www.oecd.org/dataoecd/22/63/45390367.pdf.

Arif, U., and E. Ahmad, 2012, Pension reforms: A case for Pakistan, 2012, Journal of Economics Cooperation and Development, 33(1), 113-148.

Ariff, M., and V. Marisetty, 2012, Panel Data Approach to identify factors Correlated with Equity Market Risk Premiums in Developed and Emerging markets, Quantitative Finance, 12(1), 107-118.

Bashir, M., and W. Nawang, 2011, Islamic and Conventional Unit Trusts in Malaysia:A Performance Comparison, Journal of Islamic Economics, Banking and Finance, 7(4), 9-24.

Basu, A., B. Doran and M. Drew, 2012, Sequencing Risk: The Worst Returns in their Worst Order, Finsia (Financial Services Association of Australasia), Sydney.

Basu, A., and M. Drew, 2009, The Case for Gender-Sensitive Superannuation Plan Design, Australian Economic Review, 42(2), 177-189.

Basu, A., and M. Drew, 2009(b), Portfolio Size and Lifecycle Asset Allocation in Pension Funds, Journal of Portfolio Management, 35(3), 61-72.

Basu, A., and M. Drew, 2010, The Appropriateness of Default Investment Options in Defined Contribution Plans: Australian Evidence, Pacific Basin Financial Journal, 18(3), 290-305. 
Basu, A., A. Byrne and M. Drew, 2011, Dynamic lifecycle strategies for target date retirement funds, Journal of Portfolio Management, 37(2), 83-96.

Bodie, Z., D. McLeavey, and L. B. Siegel, eds, 2008. Journal, 2 edition. (CFA Institute, New York).

Bodie, Z., R. C. Merton, and W. F. Samuelson, 1992. Labor Supply Flexibility and Portfolio Choice in a Life Cycle Model, Journal of Economic Dynamics and Control 16, 427 449.

Butler, S., C. Simpson, and A. Ziff, 2010. Exploring demand for Shariah compliant pension funds (Ipsos MORI Social Research Institute for NEST (National Employment Savings Trust, UK) London.

Byrne,A., D. Blake, A. Cairns and K. Dowd, 2006, There's no time like the present: the cost of delaying retirement saving, Financial Services Review, 15(3), 213-231

Choudhry, M. A. (n.d.). Dispensation of Wealth in Islam Retrieved August 20, 2011 from http://www.google.com/url?sa=D\&q=http://www.nd.edu/ ethics/wcConference/pre sentations/Choudhury/Choudhury+Wealth+Creation+in+I\&usg=AFQjCNFG5vzMJ vfac2tyLXX0SLLfuawoDA

Derigs, U. and S. Marzban, 2008, Review and analysis of current Shariah-compliant equity screening practices, International Journal of Islamic and Middle Eastern Finance and Management, 1(4), 285-303.

Derigs, U. and S. Marzban, 2009, New strategies and a new paradigm for Shariah-compliant portfolio optimization, Journal of Banking and Finance, 33(6), 1166-76.

Dimson, E., P. Marsh, and M. Staunton, 2002, Triumph and the Optimists: 101 Years of Global Investment Returns. Princeton University Press, Princeton, NJ.

Dow Jones. 2012. DowJones Islamic Market (DJIM) indexes. Dow Jones \& Company, accessed at: http://www.djindexes.com/islamic/index.cfm?go=overview

Drew, M., and J. Stanford, 2003, Principal and Agent Problems in Superannuation Funds, Australian Economic Review, 36(1), 108-117

Drew, M., and J. Stanford, 2003b, Returns from investing in Australian equity superannuation funds, 1991-1999, Service Industries Journal, 23(4), 12-24.

Doran, B., M. Drew and A. Walk, 2012, The Retirement Risk Zone: A Baseline Study,JASSA The Finsia Journal of Applied Finance, no. 1, pp. 6-11.

Elfakhani, S., and M. Hassan, 2007, Islamic mutual funds, in M. Hassan, and M. Lewis, eds, Handbook of Islamic Banking, Edward Elgar Publishing Limited, Cheltenham.

Elgari, M. A. (2004). Islamic Equity Investment. In S. Archer \& R. A. Abdel Karim (Eds.), Islamic Finance: Innovation and Growth. London: Euromoney Books and AAOIFI.

Finke, M., W. Pfau, D. Williams, 2012, Spending Flexibility and Safe Withdrawal Rates, Journal of Financial Planning, 25(3), 44-51. 
Frank, L., J. Mitchell, and D. Blanchett, 2010, Sequence Risk: Managing Retiree Exposure to Sequence Risk through Probability of Failure Based Decision Rules. Retrieved from http://www.academyfinancial.org/10Conference/10Proceedings/(1D)\%20Frank, $\% 2$ 0Mitchell, \%20Blanchett.pdf.

Frank, L., J. Mitchell, and D. Blanchett, 2011, An Age-Based, Three Dimensional, Universal Distribution Model Incorporating Sequence Risk. Retrieved from http://www.betterfinancialeducation.com/files/11065/AFS\%20Paper\%20Submissio n\%20Oct $\% 202011 \% 20$ Las\%20Vegas.pdf.

Hirt, G. A., S. B. Block, and S. Basu, 2006. Investment Planning for Financial Professionals(McGraw-Hill Professional, New York).

Hoepner, A., H. Rammal, and M. Rezec, 2011, Islamic mutual funds' financial performance and international investment style: evidence from 20 countries, European Journal of Finance, 17(9-10), 828-850.

Ibbotson, R. G., M. A. Milvesky, P. Chen, and K. X. Zhu, 2008. Lifetime Financial Advice: Human Capital, Asset Allocation and Insurance (CFA Institute).

Iqbal, M., and R. Wilson, 2005. Islamic Perspectives on Wealth Creation Edinburgh: Edinburgh University Press.

Iqbal, Z. (1999). Financial Engineering in Islamic Finance. Thunderbird International Business Review, 41(4/5), 541-560.

Iqbal, Z., and A. Mirakhor, 2004. The development of Islamic financial institutions and future challenges. In S. Archer \& R. A. Abdel Karim (Eds.), Islamic Finance: Innovation and Growth. London: Euromoney Books.

International Monetary Fund, 2012, The Financial Impact of Longevity Risk (Chapter 4), Global Financial Stability Report, Monetary and Capital Markets Department on Market Developments and Issues, Washington.

Jaffer, S. (2004). Editor's Introduction. In S. Jaffer (Ed.), Islamic Asset Management (1 ed., pp. xx-xxii). London: Euromoney Books.

Johnston, K., J. Hatem, C. Thomas, 2010, Investor Education: How Plan Sponsors Should Report your Returns, Managerial Finance, 36(4), 354-363.

Kotlikoff, L. J., 2008. Is Conventional Financial Planning Good for your Financial Health? (CFA Institute, New York).

Lewis, M. K. (2005). Wealth Creation through Takaful. In M. Iqbal \& R. Wilson (Eds.), Islamic Perspectives on Wealth Creation (pp. 167-187). Edinburgh: Edinburgh University Press. 
Mansor, F., and M. I. Bhatti, 2011, Risk and Return Analysis on Performance of the Islamic mutual funds: Evidence from Malaysia, Global Economy and Finance Journal, $4(1), 19-31$.

Mehra, R., and E. Prescott, 2003, The equity risk premium in retrospect, in G. M. Constantinides, M. Harris, and R. M. Stulz, eds, Handbook of the Economics of Finance: Volume $1 B$ Financial Markets and Asset Pricing. Elsevier, Amsterdam.

Modigliani, F., 1966. The Life Cycle Hypothesis of Saving, the Demand for Wealth and the Supply of Capital, Social Research, Summer.

Munnel, A., and A. Sunden, 2006, 401(k) plans are still coming up short. Issues in Brief No. 43. Centre for Retirement Research at Boston College, Boston.

OECD Directorate for Financial and Enterprise Affairs, 2011, Pension Markets in Focus, Issue 8 (July), accessed at: http://www.oecd.org/dataoecd/63/61/48438405.pdf

Pollard, J., and M. Samers, 2007. Islamic banking and finance: post-colonial political economy and the decentring of economic geography, The Institute of British Geographers, 313-330.

Poterba, J. M., J. Rauth, S. F. Venti, and D. A. Wise, 2009. Lifecycle Asset Allocation Strategies and the Distribution of $401(\mathrm{k})$ Retirement Wealth. University of Chicago Press, Chicago

Sadeghi, M., 2008, Financial Performance of Shariah-Compliant Investment: Evidence from Malaysian Stock Market, International Research Journal of Finance and Economics, 20, 15-26.

Samuelson, P. A., 1969. Lifetime Portfolio Selection by Dynamic Stochastic Programming, Review of Economics and Statistics 51, 239-246.

Sandwick, J. A., 2009. Islamic Wealth Management. In H. Dar \& U. Moghul (Eds.), The Chancellor Guide to the Legal and Shari'ah Aspects of Islamic Finance (pp. 105126). London: Chancellor Publications.

Sandwick, J. A., 2010. Islamic Asset Management: A review of the Industry. In H. Dar \& T. Azami (Eds.), Global Islamic Financial Report (pp. 71-78). London: BMB Islamic, UK.

Sandwick, J. A., 2011. Managing Shariah-Compliant Portfolios: The Challenges, the Process, and the Opportunities. Retrieved November 20, 2011 http://www.qfinance.com/contributor-biographies/john-sandwick

Thaler, R. H., 1993. Advances in Behavioural Finance (Russell Sage Foundation, New York).

Tversky, A., and D. Kahneman, 1986. Rational choice and the framing of decisions, Journal of Business 59, 251-278. 
Woerheide, W., D. Nanigian, 2012, Sustainable Withdrawal Rates: The Historical Evidence on Buffer Zone Strategies, Journal of Financial Planning, 20(5), 46-52.

U.S. Department of Commerce, United States Census Bureau, 2011, Selected Characteristics of People 15 Years Old and Over by Total Money Income in 2010, Work Experience in 2010, Race, Hispanic Origin, and Sex, United States Government, Retrieved from http://www.census.gov/hhes/www/cpstables/032011/perinc/new01_004.htm.

U.S. Department of Labor, Bureau of Labor Statistics, 2012, Usual Weekly Earnings of Wage and Salary Workers First Quarter 2012, USDL-12-0715, United States Government, Retrieved from http://www.bls.gov/news.release/archives/wkyeng_04172012.pdf.

\section{Appendices}

\section{Appendix One}

\section{Wage Earnings Profile}

Following Byrneet al., (2006) we assume an age-real earnings profile our 'typical' employee, where “... earnings follow the path of the curve as the employee grows older but are also subject to additional real growth on account of economy-wide productivity gains (p. 217)." As noted in the study, we assume, in addition to the humped wage growth profile, a two per cent per annum increase in the level of wages due to aggregate productivity advancements along with a 2 per cent per annum inflation growth assumption.

Figure A1: Humped wage growth profile

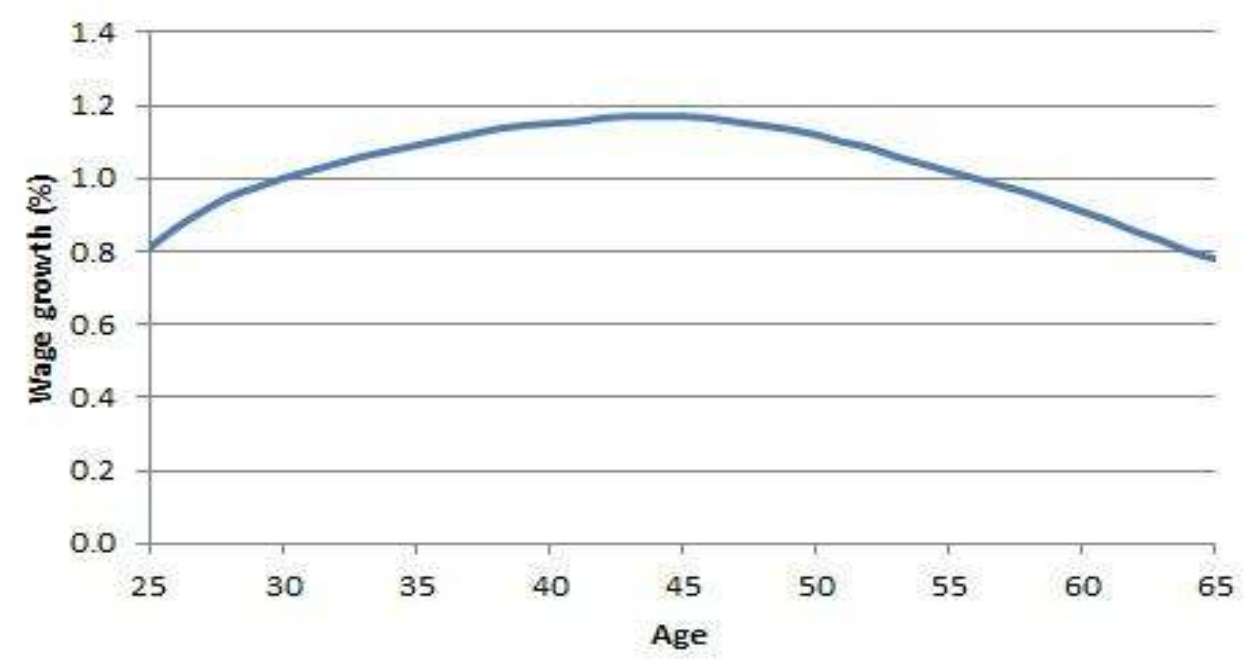

